\title{
Influence of both $\gamma$ ' distribution and grain size on the tensile properties of UDIMET 720Li at room temperature.
}

\author{
Jean-Roch Vaunois ${ }^{1,2, *}$, Jonathan Cormier ${ }^{1}$, Patrick Villechaise ${ }^{1}$, Alexandre Devaux ${ }^{2}$, \\ Benjamin Flageolet ${ }^{3}$ \\ ${ }^{1}$ Institut Pprime, CNRS - ENSMA - Université de Poitiers, UPR CNRS 3346; \\ Département Physique et Mécanique des Matériaux, ENSMA; \\ 1 avenue Clément Ader, BP 40109; 86961 Futuroscope Chasseneuil Cedex, France \\ ${ }^{2}$ Aubert \& Duval, Site des Ancizes; \\ BP1; 63770 Les Ancizes Cedex, France \\ ${ }^{3}$ Aubert \& Duval, Site de Pamiers; \\ 75 Bd de la Libération, BP 173; 09102 Pamiers Cedex, France \\ *Presently at ONERA; Département Matériaux et Structures Métalliques; \\ 29 Avenue de la Division Leclerc; 92320 Châtillon, France
}

Keywords: Tensile properties, Thermal treatment, $\boldsymbol{\gamma}^{\prime}$ volume fraction, $\boldsymbol{\gamma}^{\prime}$ distribution

\begin{abstract}
The tensile properties of a forged UDIMET $720 \mathrm{Li}$ alloy have been investigated at room temperature. The aim of this study was to increase both yield and ultimate tensile stresses using adequate thermal treatments.

Classical three steps heat treatments after hot forging were applied: a solution treatment followed by a quench and a two steps aging treatment. Several combinations were investigated: four hours solution treatments, either sub-solvus $(1080 \mathrm{C}-1120 \mathrm{C})$ or super-solvus (1160 C); two different cooling rates $(10 \mathrm{C} / \mathrm{min}$ or $3600 \mathrm{C} / \mathrm{min})$; four different two-steps aging treatments: 650 C/24h/Air Quench (AQ) + $760 \mathrm{C} / 16 \mathrm{~h} / \mathrm{AQ}, 760 \mathrm{C} / 16 \mathrm{~h} / \mathrm{AQ}+650 \mathrm{C} / 24 \mathrm{~h} / \mathrm{AQ}, 700 \mathrm{C} / 24 \mathrm{~h} / \mathrm{AQ}+$ $815 \mathrm{C} / 16 \mathrm{~h} / \mathrm{AQ}, 815 \mathrm{C} / 16 \mathrm{~h} / \mathrm{AQ}+700 \mathrm{C} / 24 \mathrm{~h} / \mathrm{AQ}$.

The tensile properties appeared to be maximized with the following combination of heat treatments: sub-solvus solutioning $(1120 \mathrm{C}$ or $1080 \mathrm{C})$, fast cooling rate (oil quench, 3600 $\mathrm{C} / \mathrm{min}$ ), and the $760 \mathrm{C} / 16 \mathrm{~h} / \mathrm{AQ}+650 \mathrm{C} / 24 \mathrm{~h} / \mathrm{AQ}$ aging. Both EBSD measurements and systematic stereological analyses were performed to characterize for each condition, grain size and $\gamma^{\prime}$ distribution (primary $\gamma^{\prime}$, secondary $\gamma^{\prime}$, tertiary $\gamma^{\prime}$ ), respectively. The increase of the $0.2 \%$ yield stress, is managed by a competition between keeping a small grain size (i.e. by using a low temperature sub-solvus solution treatment) and increasing the intragranular $\gamma$ ' content (i.e. by increasing the solutioning temperature).

In order to evaluate the relative contributions to the deformation mechanisms of grain size and of $\gamma^{\prime}$ particles, especially intergranular one (primary $\gamma^{\prime}$ ), Scanning Electron Microscope (SEM) insitu tensile tests have been performed at room temperature on both sub- and super-solvus samples. It is finally demonstrated that the main controlling parameter to reach a very high yield stress is grain size.
\end{abstract}

\section{Introduction}

UDIMET 720Li (U720Li) is a high strength nickel based superalloy developed in the 70's [1] and used for turbine disk applications in the late 90's [2]. Compared to IN718, U720Li has a temperature capability of $+80 \mathrm{C}$, with a maximum service temperature close to $730 \mathrm{C}$ [3]. Its 
superior mechanical properties at high temperature result from a high volume fraction $(\approx 45 \%)$ of $\gamma^{\prime}$ phase [4], quite stable upon long time temperature exposures as long as $1000 \mathrm{~h}$ at $760 \mathrm{C} \mathrm{[3].}$ Using adequate thermo-mechanical processing routes, its high temperature mechanical properties can be optimized versus either creep or fatigue loadings $[1,5]$, using respectively a super-solvus ( $\mathrm{T}>1155 \mathrm{C}$ ) or a sub-solvus solutioning treatment.

Nonetheless, room temperature mechanical properties have also to be improved taking into consideration the resistance to burst of turbine disks in case of overspeed events, or during engine starts for example [6]. Indeed, Airworthiness Requirements impose to protect disks from burst by overspeed securities (using electronic and/or mechanical protection for example) and to demonstrate the integrity of the engine rotors at significantly higher rates than the operating rotation speed. It was recently demonstrated using modeling approaches that a reliable way to ensure the integrity to disk burst is to improve the ultimate stress (UTS), a goal which is usually associated for polycrystalline Ni-based superalloys with a yield stress (YS) improvement.

In this context, the present study focuses on the optimization of the room temperature tensile properties, especially the yield stress, by investigating several thermal treatments (both solutioning and aging treatments) performed after the forging sequence, leading to either High Strength (HS) or Creep Resistant (CR) alloys. Detailed microstructural investigations were performed to make correlation between tensile properties and microstructural characteristics such as grain size and $\gamma^{\prime}$ distribution.

\section{Experimental Procedures}

\section{$\underline{\text { Material }}$}

A cast and wrought $(\mathrm{C} \& \mathrm{~W})$ U720Li made by VIM-ESR-VAR at Aubert \& Duval, Les Ancizes was used in this study. As a reminder, the standard chemical composition is given in Table I. After last remelting, an ingot was forged on a 2500 tons press. Tensile specimens were finally extracted from a $80 \mathrm{~mm}$ bar obtained using a 4-ram hydraulic radial forging machine, called SMX (by SMS EUMUCO Inc.). SMX has advantages over classical 2-ram press or 4-ram mechanical radial forging machine (GFM): its forging speed is higher and straighter and more truly round billet can be obtained; in addition, the reduction in pass of SMX can be controlled, although that of GFM must be set a small value. Therefore SMX can easily control the forging conditions. These advantages are effective to obtain fine grains of all the regions of large section size billets [7]. After forging, the bar was air-cooled.

Table I. Chemical composition of U720Li (wt. \%)

\begin{tabular}{|c|c|c|c|c|c|c|c|c|c|c|}
\hline $\mathbf{N i}$ & $\mathbf{C r}$ & $\mathbf{C o}$ & $\mathbf{M o}$ & $\mathbf{W}$ & $\mathbf{A l}$ & $\mathbf{T i}$ & $\mathbf{C}$ & $\mathbf{B}$ & $\mathbf{Z r}$ & $\mathbf{F e}$ \\
\hline Bal. & 16.2 & 14.6 & 2.9 & 1.2 & 2.51 & 4.97 & 0.014 & $<0.03$ & $<0.06$ & $<0.2$ \\
\hline
\end{tabular}

\section{Thermal Treatments}

Solution heat treatments were performed in air at $1080 \mathrm{C}, 1120 \mathrm{C}$ and $1160 \mathrm{C}$ during $4 \mathrm{~h}$ in a furnace with a $+/-2^{\circ} \mathrm{C}$ temperature control using S-thermocouples. Either Oil Quench (OQ/ cooling rate $=3600 \mathrm{C} \cdot \mathrm{min}^{-1}$ ) or controlled Furnace Cooling (FC) at $10 \mathrm{C} \cdot \mathrm{min}^{-1}$ were performed at the end of the solutioning treatment. Aging treatments were subsequently carried out in air, at a temperature of $650 \mathrm{C}, 700 \mathrm{C}, 760 \mathrm{C}$ or $815 \mathrm{C}$ followed by Air Quench (AQ). The two first rows of Table II show the different heat treatments used in the present investigation. Either cylindrical blanks (diameter $=14 \mathrm{~mm}$, length $=72 \mathrm{~mm}$ ) or parallelepipeds (edge length $=12 \mathrm{~mm}$, length $=$ $35 \mathrm{~mm}$ ) were used for thermal treatments, before sample machining for macroscopic tensile 
characterization and SEM in-situ tensile testing, respectively. These blanks were machined out from the $80 \mathrm{~mm}$ bar at mid-radius. Average grain size in this location was determined to be 5 $\mu \mathrm{m}$.

\section{$\underline{\text { Mechanical tests }}$}

Tensile test were performed at room temperature according to the NF - EN 2002-1 procedure using specimens whose gage length and diameter were respectively $32 \mathrm{~mm}$ and $6.35 \mathrm{~mm}$. Tests were carried out under extensometer strain rate control, using a strain rate of $5.010^{-3} \mathrm{~min}^{-1}$ up to the $0.2 \%$ yield stress and a subsequent strain rate of $5.010^{-1} \mathrm{~min}^{-1}$ until failure. Tensile test were performed after each step of a given thermal treatment sequence (e.g. after solution treatment, after the first step of aging treatment and after the second step), leading to the characterization of 29 treatments.

SEM in-situ tensile tests were performed on samples which were given the aging treatment providing the highest yield stress for both sub- and super-solvus solutioning (see Table II). Experiments were performed using flat micro tensile samples machined from the above mentioned parallelepipeds by spark plasma erosion. Their gage length, width and thickness were $10 \mathrm{~mm}, 2 \mathrm{~mm}$ and $1 \mathrm{~mm}$, respectively. Samples were mechanically polished until obtaining a mirror finish (final polishing using a $1 \mu \mathrm{m}$ diamond spray). Additionally, their gage surfaces were electrochemically polished to remove any residual deformation or stress in the surface layers due to mechanical polishing. Since no extensometer can be used in our equipment during in-situ experiments, ex-situ tests were firstly performed with extensometer fixed on the gage length to precisely establish the equivalent continuous stress-strain curve for this type of sample [8]. Experiments were performed at a strain rate of $8.0 \times 10^{-5} \cdot \mathrm{s}^{-1}$. These conditions permitted to stop easily tests at a pre-determined stress or strain level, by stopping the motor, allowing the observation of several zones for the same level of elongation. Interruptions were performed every 200/300 MPa early in the elastic domain (up to $200 \mathrm{MPa}$ below YS) of the investigated microstructures. Afterwards, interruptions were made every 20/25 MPa to ensure a precise detection of the first events of plastic deformation. Finally, tests were stopped after a $0.36 \%$ and a $1.15 \%$ plastic deformation were obtained for respectively the CR and HS investigated microstructures.

\section{$\underline{\text { Microstructure characterizations }}$}

Microstructural investigations were performed in the tensile specimen heads after failure. Observations were done on longitudinal sections of the samples, after mechanical polishing up to a mirror finish. The $\gamma^{\prime}$ phase distribution was revealed by selective etching of the $\gamma^{\prime}$ particles, using a solution made of $1 / 3 \mathrm{HNO}_{3}, 2 / 3 \mathrm{HCl}$ at $4^{\circ} \mathrm{C}$ for 5 to $10 \mathrm{~s}$. Electrochemical polishing at $4^{\circ} \mathrm{C}$ and $45 \mathrm{~V}$ using a solution made of $10 \%$ perchloric acid in methanol was used to characterize the grain size by EBSD. Such a polishing was also applied to the tensile micro samples used for SEM in-situ experiments.

Three Scanning Electron Microscopes (SEM) were used in the study. Primary $\left(\gamma_{\mathrm{I}}\right)$ and coarse secondary $\left(\gamma_{\text {II }}^{\prime}\right) \gamma^{\prime}$ particles (average radius $>200 \mathrm{~nm}$ ) were characterized using the secondary electron mode (SEI) of a JEOL 6400 operating in the range 20-25 kV. Fine secondary and tertiary $\left(\gamma_{\text {III }}^{\prime}\right)$ precipitates (average radius in the range $10-200 \mathrm{~nm}$ ) were observed using a field emission gun SEM (SEM-FEG) JEOL 7000F operating at $25 \mathrm{kV}$, using magnifications up to 200,000. In-situ tensile tests were performed using either the SEI or the backscattered electron modes (BSE) of a JEOL 6100 SEM operating at $25 \mathrm{kV}$. Both grain sizes and orientation maps 
were carried out using the above mentioned SEM-FEG with scanning steps of $0.2 \mu \mathrm{m}$ and $5 \mu \mathrm{m}$ for the sub-solvus and the super-solvus microstructures, respectively.

Stereological analyzes of the $\gamma^{\prime}$-phase were performed using Visilog ${ }^{\circledR}$ software. Both area fraction, $\gamma^{\prime}$ particles size distribution and interparticle spacing distribution were obtained using the following algorithm [9]: i) contours smoothing + contrast enhancement + contrast inversion (Fig. 1b), ii) brightness thresholding (Fig. 1c); iii) erosion and homothetic reconstruction to erase some uncharacteristic particles of the microstructure (+ border kill); iv) individual particle separation and characterization; v) skeleton and detection of the interprecipitate spacings (Fig. 1d). The "border kill" function consists of an erosion of all the particles having connexion with the image sides. This function was hence only applied in case of $\gamma^{\prime}$ size characterization and not for area fraction (AF) determination. It should be noted that area fractions were measured for each class of $\gamma$ ' precipitates by performing selective erosion. For each studied condition, $\gamma$ ' size distribution and area fraction were based on a statistic including at least 5000 particles.
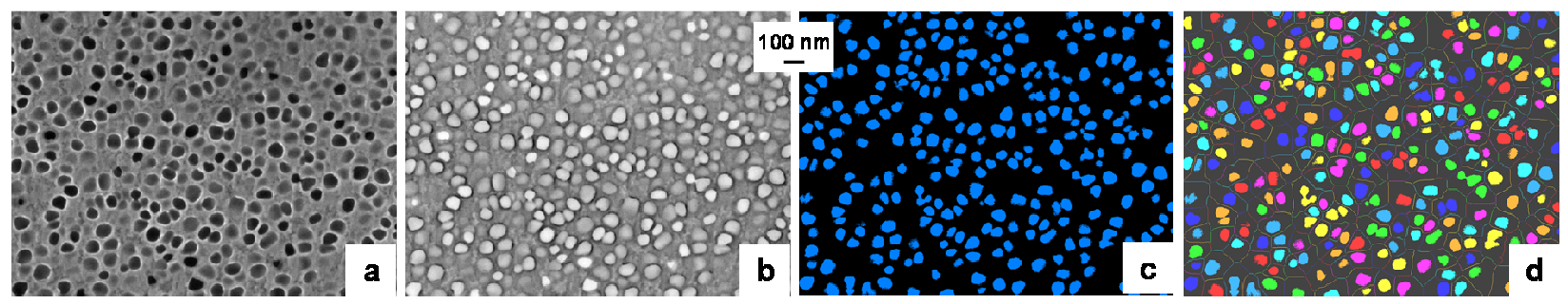

Figure 1. Image analysis sequence: SEM initial image (a); image after contrast inversion (b); image after thresholding and erosion (c); particle and interparticle analysis (d).

\section{Results}

\section{$\underline{\text { Grain size }}$}

The grain size after each solution treatments was investigated using large EBSD scans. Figure 2 shows the grain structure after $1080 \mathrm{C}, 1120 \mathrm{C}$ and $1160 \mathrm{C}$ solutioning treatments (ST). Average grain sizes were determined to be $4.8 \mu \mathrm{m}(\operatorname{Min}=2.8 \mu \mathrm{m} / \mathrm{Max}=12.5 \mu \mathrm{m}), 12.9 \mu \mathrm{m}(\mathrm{Min}=3.1$ $\mu \mathrm{m} / \mathrm{Max}=30 \mu \mathrm{m})$ and $456 \mu \mathrm{m}(\operatorname{Min}=45 \mu \mathrm{m} / \mathrm{Max}=1018 \mu \mathrm{m})$, respectively. Figure 3a presents the evolution of the average grain size as a function of solutioning temperature. It is observed a relatively good agreement with data available in the literature $[1,10,11]$.

\section{$\gamma^{\prime}$ distribution and interparticle spacing characterization}

Results of the stereological analyses of the $\gamma^{\prime}$ phase performed focusing on all particle classes (primary, secondary and tertiary), as well as average interprecipitate spacing (i.e. average distance in between the smallest $\gamma^{\prime}$ precipitates) are presented in Table II. It was decided to divide secondary $\gamma^{\prime}$ particles into two classes: secondary $\gamma^{\prime}$ undissolved during solution treatment (denoted in the following as $\gamma_{\text {IIu }}^{\prime}$ ) and secondary $\gamma^{\prime}$ forming upon cooling from the ST (denoted in the following as $\gamma_{\text {IIc }}^{\prime}$ ). Following this convention, tertiary $\gamma^{\prime}\left(\gamma_{\text {III }}^{\prime}\right)$ are particles whose nucleation occurs during aging treatment or late (i.e. at low temperature) upon cooling from ST to room temperature, during a second nucleation burst [12]. Microstructures at different magnifications and for several thermal treatments are presented in Figure 4. Due to difficulties in the quantification of the $\gamma^{\prime}$ AF of the smallest particles (especially $\gamma_{\text {III }}^{\prime} \mathrm{AF}$ ), it was chosen to 
consider their AF as the balance between the $\gamma^{\prime}$ volume fraction at thermodynamic equilibrium at room temperature (45\%) and the AF of primary and secondary $\gamma^{\prime}$. Such difficulties can easily be pointed out on Figure 4 for the thermal treatment 4h $1160 \mathrm{C} / \mathrm{OQ}+16 \mathrm{~h} 760 \mathrm{C} / \mathrm{AQ}+24 \mathrm{~h} 650$ $\mathrm{C} / \mathrm{AQ}$, where ultrafine particles $(11 \mathrm{~nm}$ in average diameter) are evidenced in between the secondary $\gamma$, and whose AF cannot be quantified satisfactorily.

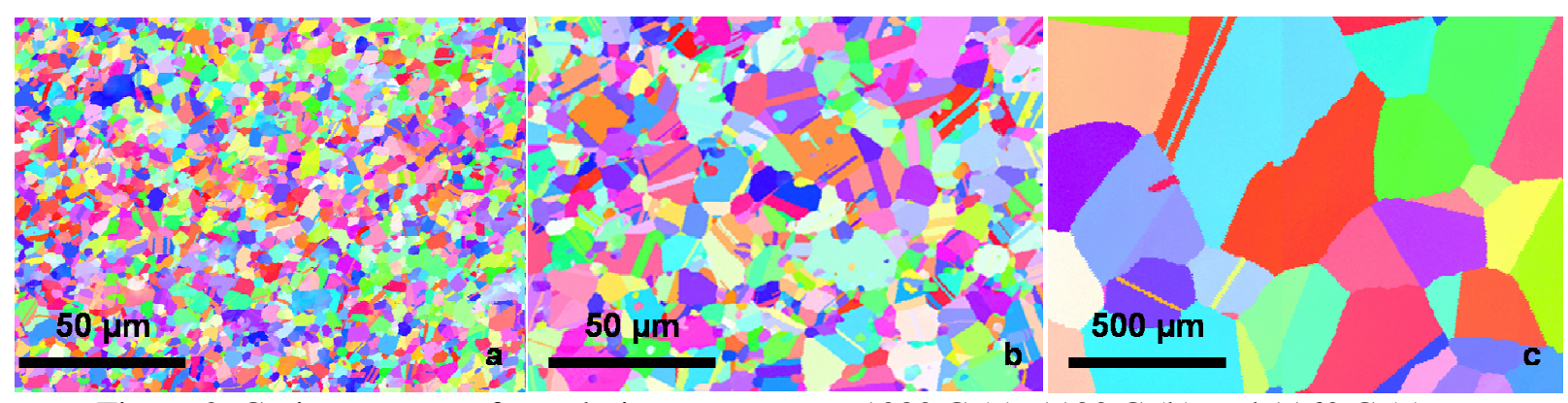

Figure 2. Grain structure after solution treatment at $1080 \mathrm{C}$ (a), $1120 \mathrm{C}$ (b) and $1160 \mathrm{C}$ (c)

\section{Primary $\gamma^{\prime}$ quantification $\left(\gamma_{\mathrm{I}}^{\prime}\right)$}

The evolution of primary $\gamma^{\prime} \mathrm{AF}$ and average diameter (magnified 5 times) as a function of the solutioning temperature are presented in Figure 3b, after the aging treatment 16h $760 \mathrm{C} / \mathrm{AQ}+$ 24h $650 \mathrm{C} / \mathrm{AQ}$. Those results, which are in relatively good agreement with Jackson and Reed [11], show a decrease of the AF with increasing solutioning temperature. In addition, it is observed some coarse remaining $\gamma_{\text {I }}^{\prime}$ after a $1160 \mathrm{C}$ solutioning, as illustrated in Figure 4 for the super-solvus solution treatment followed by oil quench. Since Figure $3 \mathrm{~b}$ also shows that the average diameter of $\gamma_{\mathrm{I}}^{\prime}$ is increasing with solution temperature, it can be deduced that the duration used for the solution treatment is not sufficient to allow the dissolution of the biggest primary $\gamma^{\prime}$ particles. In addition, it is observed in Figure $3 \mathrm{~b}$ that increasing the solution temperature leads to a progressive deviation between $\gamma_{\mathrm{I}}^{\prime} \mathrm{AF}$ and the volume fraction at thermodynamical equilibrium (VF) predicted using Thermocalc with the database Ni-data v4. The progressive convergence with increasing solution temperature corresponds to the dissolution of undissolved secondary $\gamma^{\prime}\left(\gamma_{\text {IIU }}^{\prime}\right)$ during higher temperature ST.
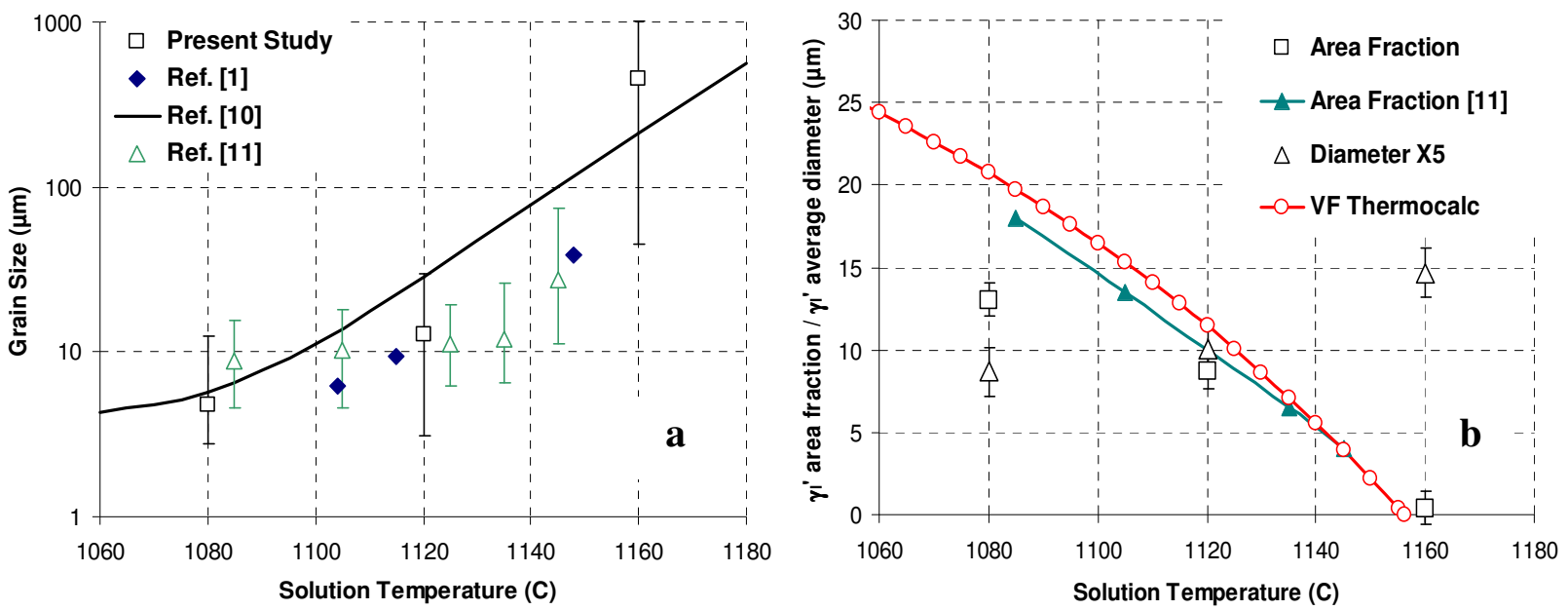

Figure 3. Average grain sizes (a), primary $\gamma^{\prime}$ area fraction and average diameter (b) evolution as of function of the solution temperature 
Table II. Room temperature tensile properties, average particle distance, area fraction (AF) and average diameter of primary $\gamma^{\prime}\left(\gamma_{\mathrm{I}}^{\prime}\right)$, secondary $\gamma^{\prime}\left(\gamma_{\text {II }}^{\prime}\right)$ and tertiary $\gamma^{\prime}\left(\gamma_{\text {III }}^{\prime}\right)$.

\begin{tabular}{|c|c|c|c|c|c|c|}
\hline $\begin{array}{l}\overline{8} \\
8 \\
\delta \\
\delta\end{array}$ & 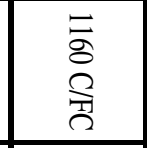 & 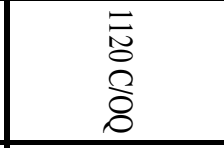 & $\begin{array}{l}\overrightarrow{8} \\
\stackrel{8}{0} \\
\stackrel{2}{8} \\
\end{array}$ & $\begin{array}{l}\vec{\circ} \\
\stackrel{\circ}{0} \\
\stackrel{1}{1} \\
\text { 己े }\end{array}$ & 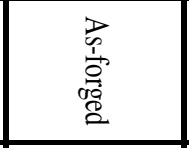 & 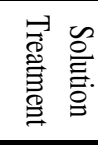 \\
\hline 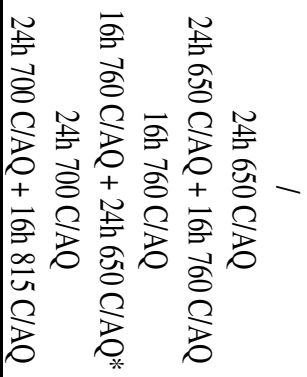 & 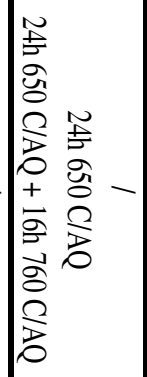 & 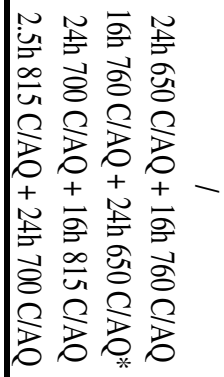 & 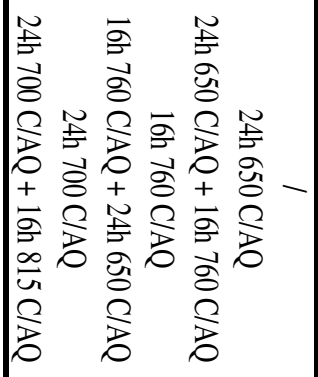 & 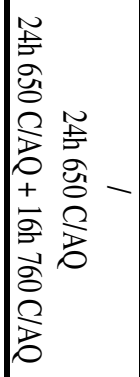 & 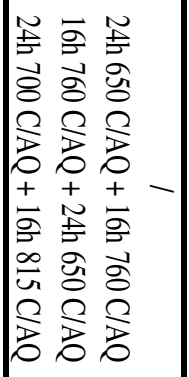 & 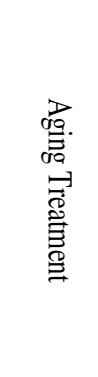 \\
\hline 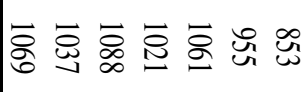 & ఫ্ర & 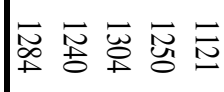 & 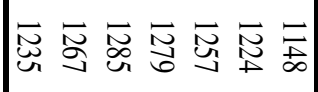 & 㣽 & 言 㥕 & 蛋出 \\
\hline 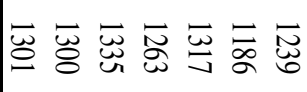 & 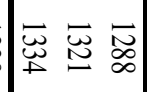 & 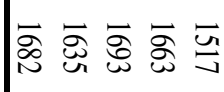 & 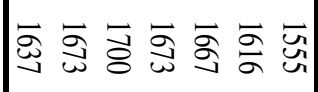 & 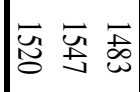 & 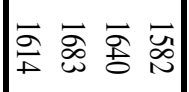 & 胥露 \\
\hline 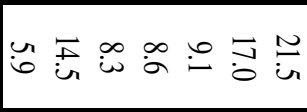 & $\nabla \stackrel{0}{0} \underset{0}{N}$ & 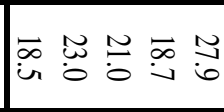 & 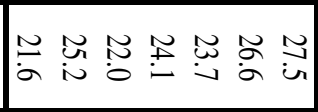 & 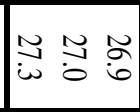 & 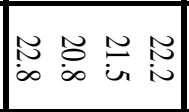 & ब을 \\
\hline 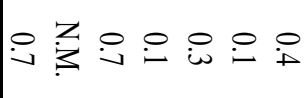 & 을 至 & 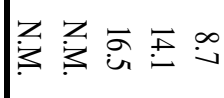 & 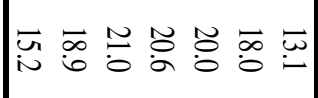 & 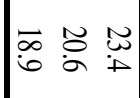 & 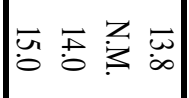 & $\vec{a}^{2}$ \\
\hline 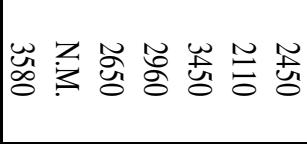 & 点 忍 & 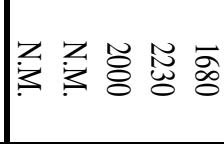 & 岕 & 方 & 芯 & 寒总 \\
\hline$-\cdots$ & $\ldots$ & $\cdots \cdots$ & 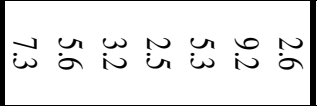 & 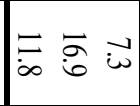 & 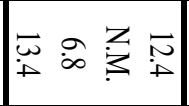 & $\vec{a}^{a^{2}}$ \\
\hline & & & $\tilde{U}$ & 志 岕 岕 & 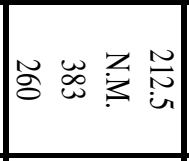 & 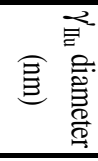 \\
\hline 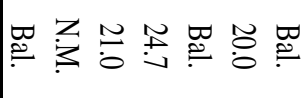 & $\mid \begin{array}{l}w \\
\sigma \\
\alpha\end{array}$ & 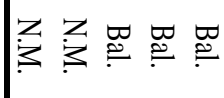 & 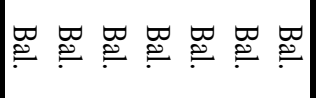 & $\mid$\begin{tabular}{ll}
$z$ & $z$ \\
\hdashline & 3 \\
\hdashline & 3
\end{tabular} & 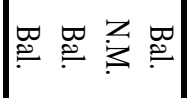 & 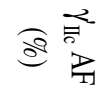 \\
\hline 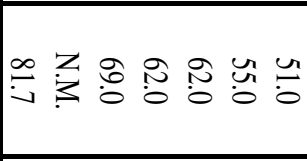 & 岗 & 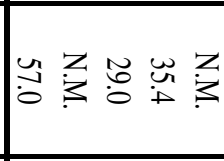 & 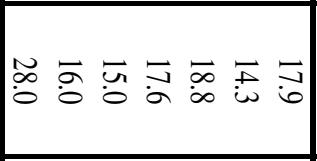 & 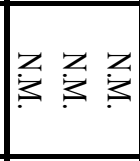 & $\mid \begin{array}{ll}z \\
3 \\
3\end{array}$ & 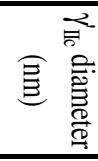 \\
\hline - & 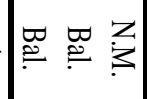 & - & $-\cdots$ & 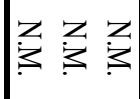 & - & 产 \\
\hline - & 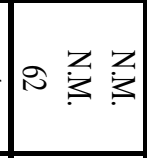 & & - & $\mid$\begin{tabular}{lll}
$z$ & $z$ \\
3 & $z$ & $z$ \\
\hdashline & 3
\end{tabular} & & 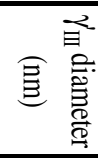 \\
\hline 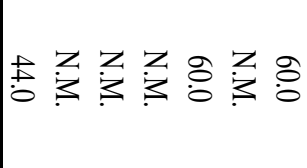 & $\mid$\begin{tabular}{lll}
$z$ & $z$ & $z$ \\
3 & 3 & 3 \\
\hdashline & 3
\end{tabular} & 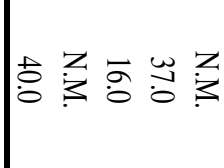 & 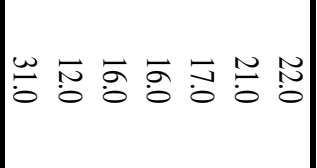 & 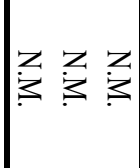 & ž & 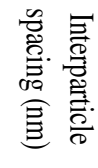 \\
\hline
\end{tabular}

N.M.: Not Measured; /: nothing to analyze; Bal.: Balance.

* Thermal treatments used for SEM in-situ tensile characterization 


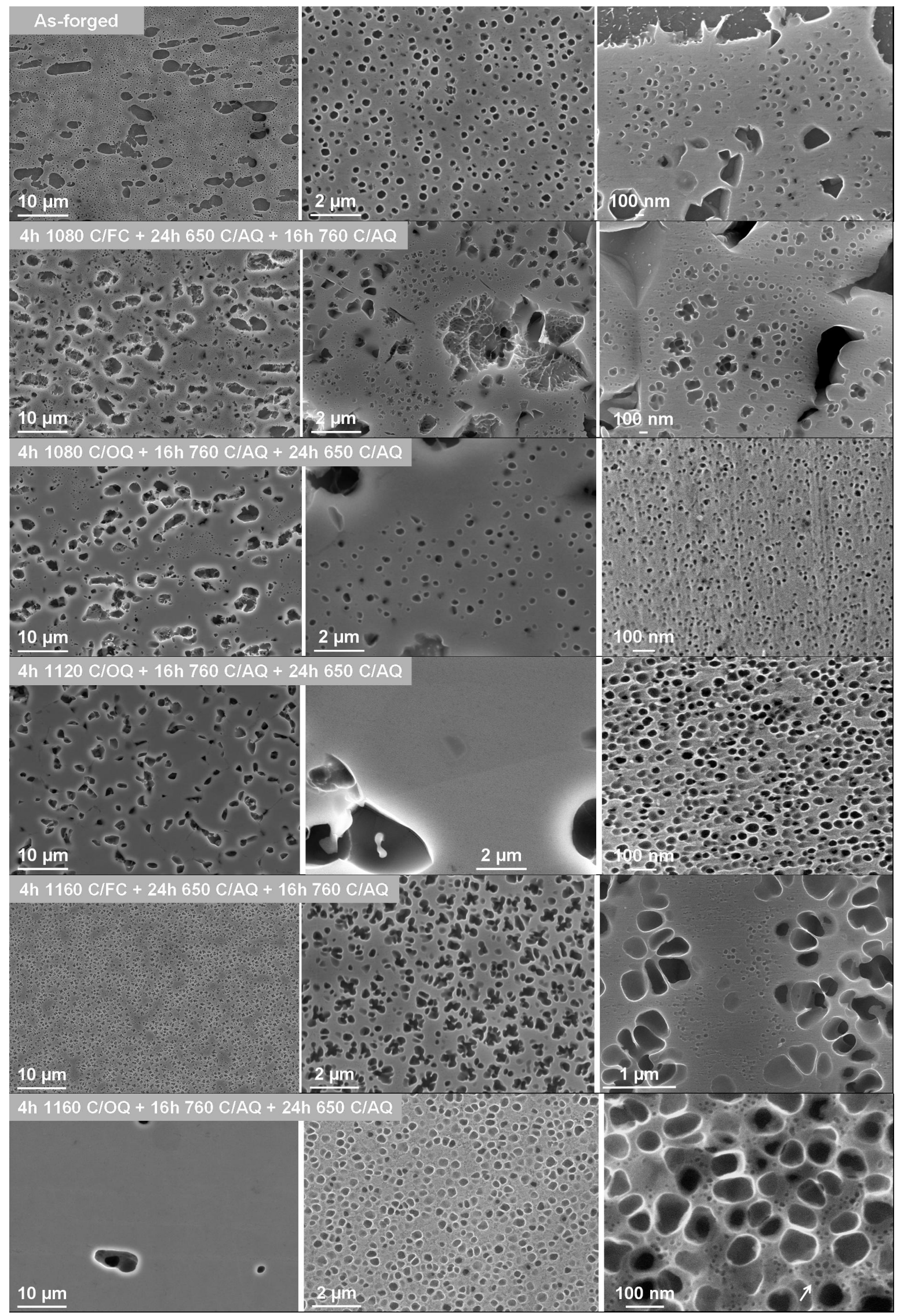

Figure 4. $\gamma / \gamma^{\prime}$ microstructures of U720 Li at different magnifications in the as-forged bar or after different thermal treatments. 


\section{Secondary $\gamma^{\prime}$ characterization $\left(\gamma_{\text {IIc }}^{\prime}\right)$}

It has been demonstrated that the size of $\gamma_{\text {IIc }}^{\prime}$ is closely related to cooling rate after ST [13]. Indeed secondary gamma prime particles grow after initial nucleation and therefore their size is controlled by a diffusion process. In addition, it was measured, using dilatometric experiments, that increasing the cooling rate $\dot{\mathrm{T}}_{\mathrm{c}}$ leads to a lower nucleation temperature for $\gamma_{\text {IIc }}^{\prime}$ [14]. Therefore, average secondary $\gamma^{\prime}$ precipitates diameters grow with lower cooling rates. Such consideration is confirmed by Figure 5 where our results are compared to data available in the literature for either sub-solvus alloys [11], or super-solvus ones [10, 12, 13, 15]. Power law dependence of the average diameter $d$ to the cooling rates $\dot{T}_{c}$ for both solution treatments has been added in this figure (red and black solid lines for respectively super- and sub-solvus solutioning), using the following equation:

$$
\mathrm{d}=\alpha \times\left(\dot{\mathrm{T}}_{\mathrm{c}}\right)^{-\beta}
$$

It was identified over the whole database $(\alpha, \beta)$ values of $(326.41,0.2542)$ and $(840.88,0.3113)$ for sub- and super-solvus solution treatment respectively, excluding super-solvus heat treatments performed by Furrer and Fecht on a powder metallurgy U720Li which lead to higher particle sizes [10].

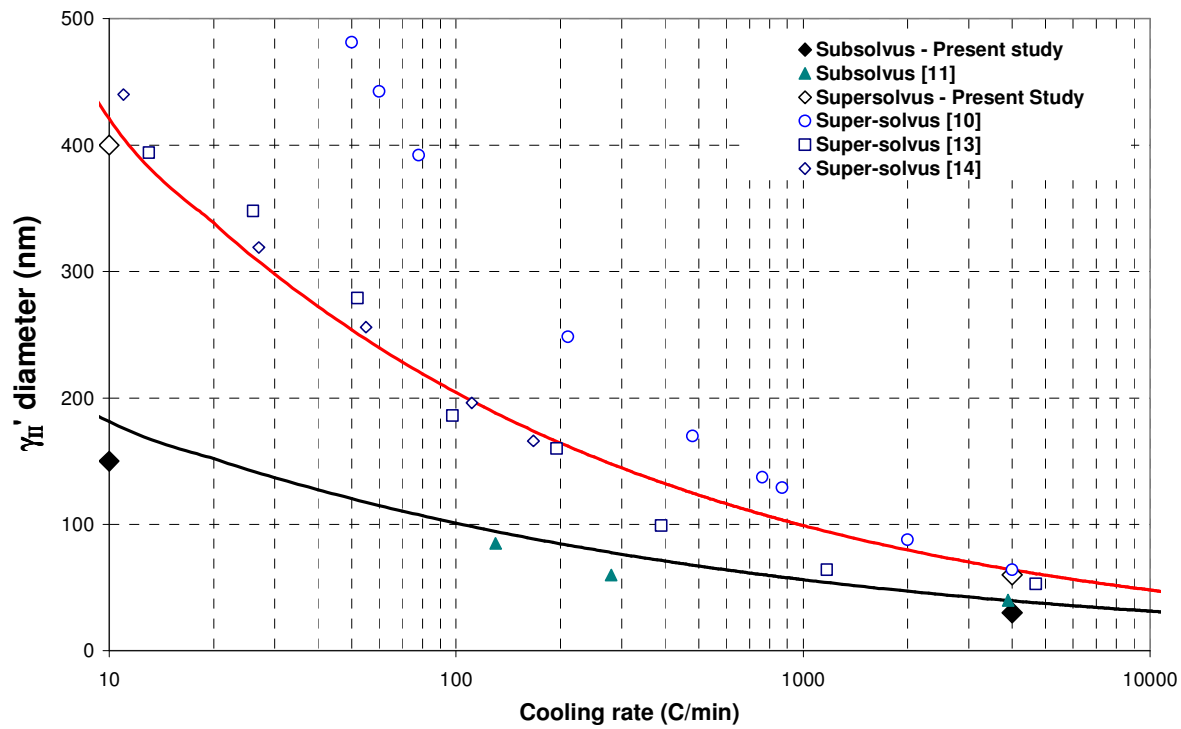

Figure 5. Secondary $\gamma^{\prime}$ diameter as a function of the cooling rate from the solution temperature.

\section{Effect of aging and solution treatment on $\gamma_{\text {IIc }}^{\prime}$ and tertiary $\gamma^{\prime}\left(\gamma_{\text {IIII }}^{\prime}\right)$}

Both secondary $\gamma_{\text {IIc }}^{\prime}$ and tertiary $\gamma^{\prime}$ particles (i.e. particles whose average diameter is below 80 $\mathrm{nm}$ ) have been characterized focusing on either the effect of the ST (Fig. 6a) or on the effect of the aging treatment after the same ST 4h 1080 C/OQ (Fig. 6b). For both selected aging treatments (16h $760 \mathrm{C} / \mathrm{AQ}+24 \mathrm{~h} 650 \mathrm{C} / \mathrm{AQ}$ and 24h $650 \mathrm{C} / \mathrm{AQ}+16 \mathrm{~h} 760 \mathrm{C} / \mathrm{AQ})$, it is observed an increase of both the diameter and area fraction of these hyperfine $\gamma^{\prime}$ (Fig. 6a). The only reasons for an increase of both their AF and diameter are: (i) the increase of intragranular $\gamma^{\prime}$ volume fraction due to the dissolution of primary $\gamma^{\prime}$ at higher ST, and (ii) a nucleation burst of 
those $\gamma^{\prime}$ precipitates at higher temperature due to a higher $\gamma^{\prime}$ supersaturation of the matrix during cooling from a super-solvus state, respectively.

Focusing on the effect of the aging treatment (Fig. 6b), no clear effect on either these classes of $\gamma^{\prime}$ precipitates AF or diameter could have been noticed. It is only observed a slight particle size increase with the aging treatment $24 \mathrm{~h} 700 \mathrm{C} / \mathrm{AQ}+16 \mathrm{~h} 815 \mathrm{C} / \mathrm{AQ}$, where the higher average temperature leads to higher precipitates sizes, according to LSW theory $[16,17]$.
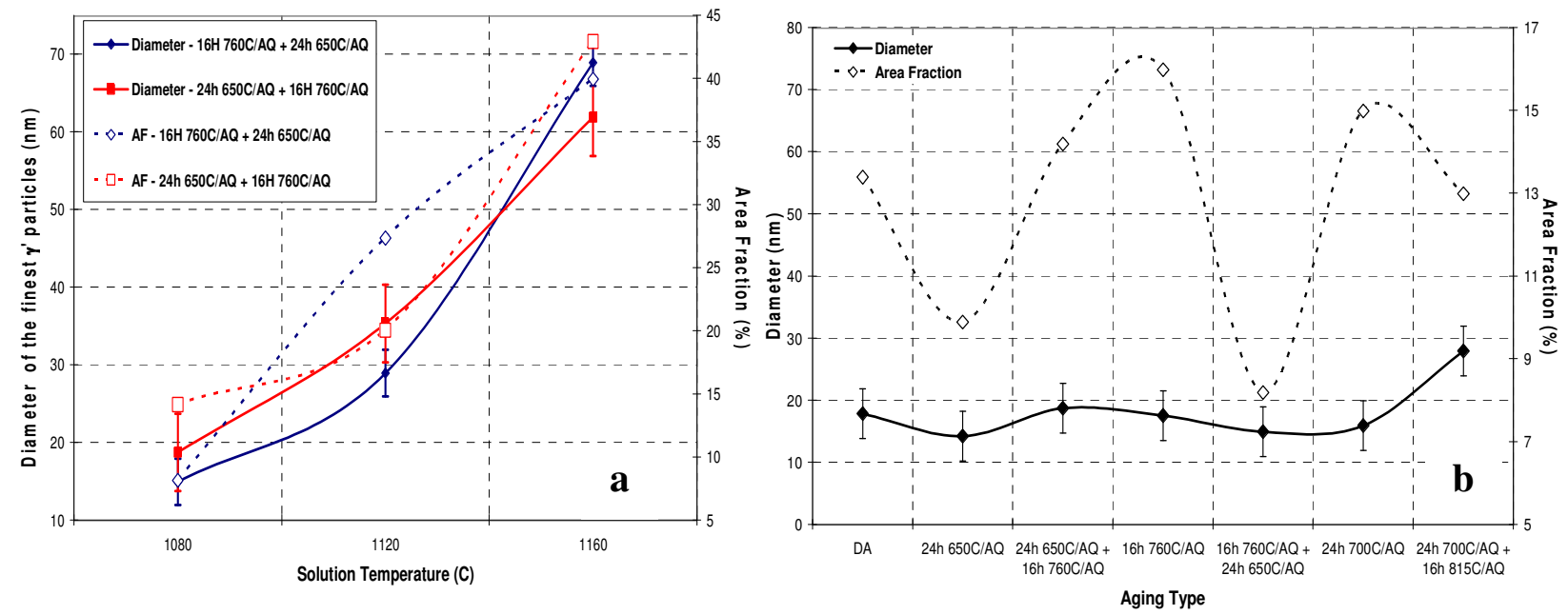

Figure 6. Evolution of $\left(\gamma_{\text {IIc }}^{\prime}+\gamma_{\text {IIII }}^{\prime}\right)$ AF and average diameter as a function of the solution temperature (a) or as a function of different aging treatments after a $1080 \mathrm{C} / \mathrm{OQ}$ solution treatment (b).

\section{$\underline{\text { Tensile properties }}$}

$0.2 \%$ yield stress (YS) and UTS values for the investigated thermal treatment sequences are presented in the $3^{\text {rd }}$ and $4^{\text {th }}$ columns of Table II, respectively. To get a better understanding, Figure 7 plots room temperature YS and UTS as a function of the solution temperature (ST followed by $\mathrm{OQ}$ ) for various aging treatments. The as-forged properties including aging heat treatments, without however ST, have be denoted in this figure as Direct Aged (DA) solution treatment. Independently of the ST, it is observed that the aging treatment producing the highest tensile properties (both YS and UTS) is $16 \mathrm{~h} 760 \mathrm{C} / \mathrm{AQ}+24 \mathrm{~h} 650 \mathrm{C} / \mathrm{AQ}$. Moreover, it is observed that best YS and UTS are obtained for sub-solvus solution treatments (followed by Oil Quench) quite independently on the solution temperature. Rather low tensile properties obtained for the DA alloy may arise from the slow cooling rate applied to the bar after SMX forging, leading to a coarse $\gamma$ ' precipitation.

Both YS (at a $0.2 \%$ plastic strain) and UTS are in good agreement with results found in the literature for similar heat treatment schedules $[1,2,10,11]$. Only room temperature $0.2 \%$ proof stress results presented by Jackson and Reed on samples extracted from a forged billet which were given the thermal treatment sequence 4h $1105 \mathrm{C} / \mathrm{OQ}$ + various dwells at $700 \mathrm{C} / \mathrm{AQ}$ exhibit YS in the range 1425-1500 MPa [11], i.e. an average of $150 \mathrm{MPa}$ higher than our best YS results or Sczerzenie and Maurer ones [1].

Based on the results presented in Figure 7, it is observed that increasing the solution temperature from $1080 \mathrm{C}$ to $1120 \mathrm{C}$ do not produce any pronounced effect on tensile properties: for the same aging treatment producing the best $0.2 \%$ yield stresses (i.e. $16 \mathrm{~h} 760 \mathrm{C} / \mathrm{AQ}+24 \mathrm{~h} 650 \mathrm{C} / \mathrm{AQ}$ ), 
only a step of $19 \mathrm{MPa}$ difference is observed by increasing the solution temperature from $1080 \mathrm{C}$ to $1120 \mathrm{C}$. Therefore, it seems that increasing the intragranular $\gamma^{\prime}$ volume fraction by using a higher sub-solvus ST is counterbalanced by the increase of the mean grain size.

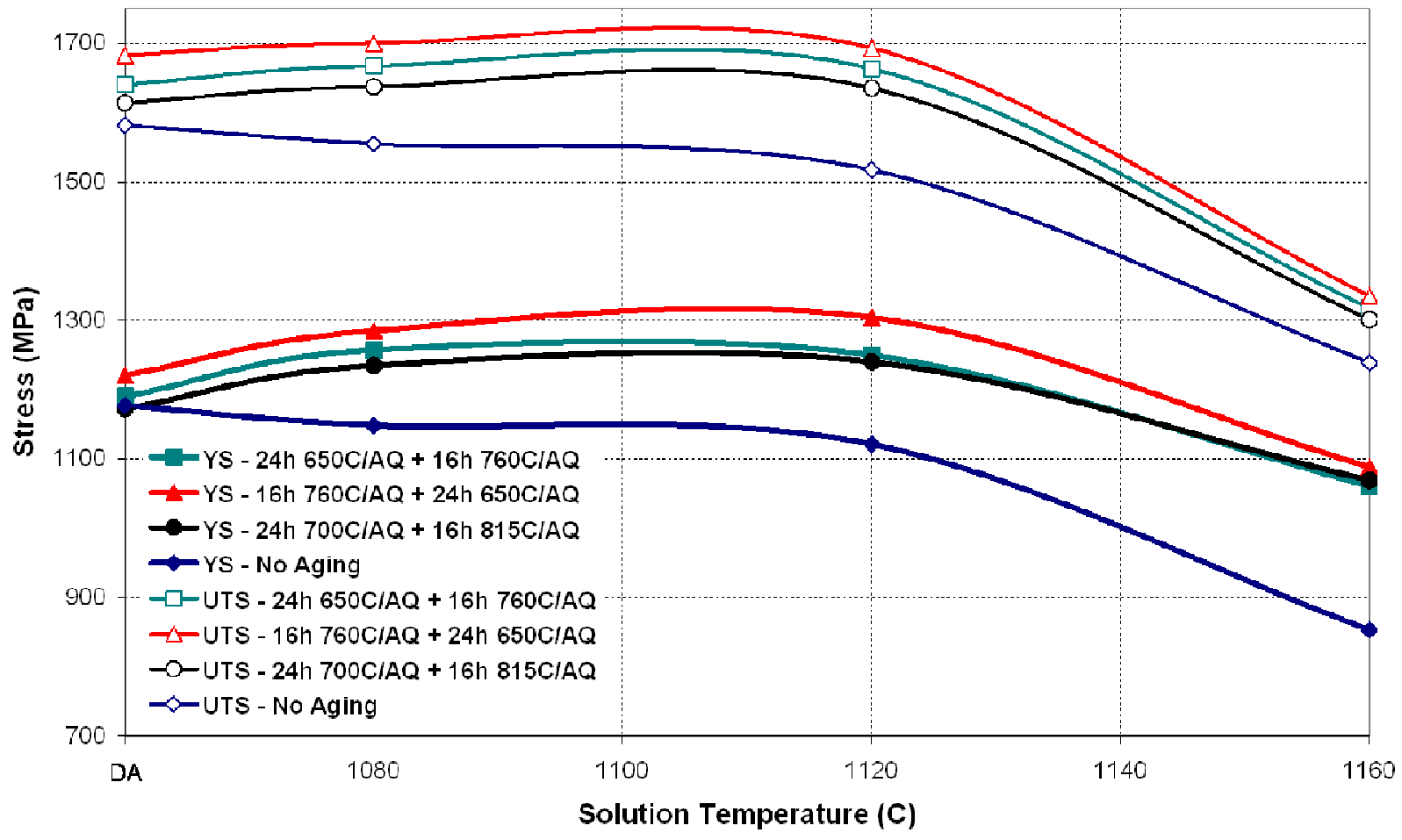

Figure 7. YS and UTS evolutions as a function of the solution temperature for different aging treatments.

Ductility was found to be quite insensitive to solution temperature and aging treatment for subsolvus heat-treatments (see Table II). However, it was noted a steep decrease of the ductility for aged super-solvus treated alloys (in case of ST followed by OQ). A reduction of more than a factor 2 was obtained compared to sub-solvus treatments, un-aged super-solvus treatments or super-solvus treatments followed by slow cooling rate (FC).

\section{$\underline{\text { SEM in-situ tensile tests }}$}

To get a better understanding of the effect of both the grain size and intragranular precipitation on the room temperature properties, it was chosen to perform SEM in-situ tensile tests on the highest YS HS alloy and on the highest YS CR alloy (see corresponding thermal treatment sequence highlighted by asterisks in Table II, and corresponding $\gamma / \gamma^{\prime}$ microstructures in the $4^{\text {th }}$ and $6^{\text {th }}$ rows of microphotographs in Figure 4, respectively). Figures 8 and 9 present the results of those experiments performed on the chosen HS and CR microstructures, respectively. Only microstructures observed at specific positions of the tensile curves are presented (see red dots in Figures 8 and 9). Applied tensile stresses are indicated on each chosen microstructure.

The first result is that SEM in-situ tensile curves (dotted curves) are close to macroscopic ones (solid curves), especially for the super-solvus heat treated alloy. It was only observed a small increase of the $0.2 \%$ yield stress for the in-situ tensile test performed on the sub-solvus microstructure (1335 MPa vs $1304 \mathrm{MPa}$ for the macroscopic test). First events of plastic deformation were detected at $900 \mathrm{MPa}$ and $1300 \mathrm{MPa}$ for the CR and the HS microstructure, respectively (see white arrows in Figures 8 and 9). Those first slip traces were therefore obtained 
$288 \mathrm{MPa}$ and $31 \mathrm{MPa}$ below $0.2 \%$ macroscopic yield stress for the $\mathrm{CR}$ and the HS microstructure, respectively. Plastic deformation is characterized by very planar slip bands, except for grains containing twins where slip traces deviate at grain/twin boundaries (see Figure 8 for example). Primary $\gamma^{\prime}$ particles were not identified to originate slip bands, especially for the first slip evidences in the sub-solvus tested alloy.

Considering the HS alloy, it is observed that plastic deformation first occur in a coarse twinned grain whose diameter is around $25-30 \mu \mathrm{m}$, i.e. twice the average grain size of the alloy (see Figs. 2 and 3a). In addition, it is observed that even at $1425 \mathrm{MPa}$, after a $1.15 \%$ macroscopic plastic deformation has been reached, some small-grained areas only present a very few number of slip traces (see dotted encircled area of the top right picture in Figure 8). Moreover, for the grains that present a plasticity activity, only one slip system is activated with a relatively limited number of slip bands.
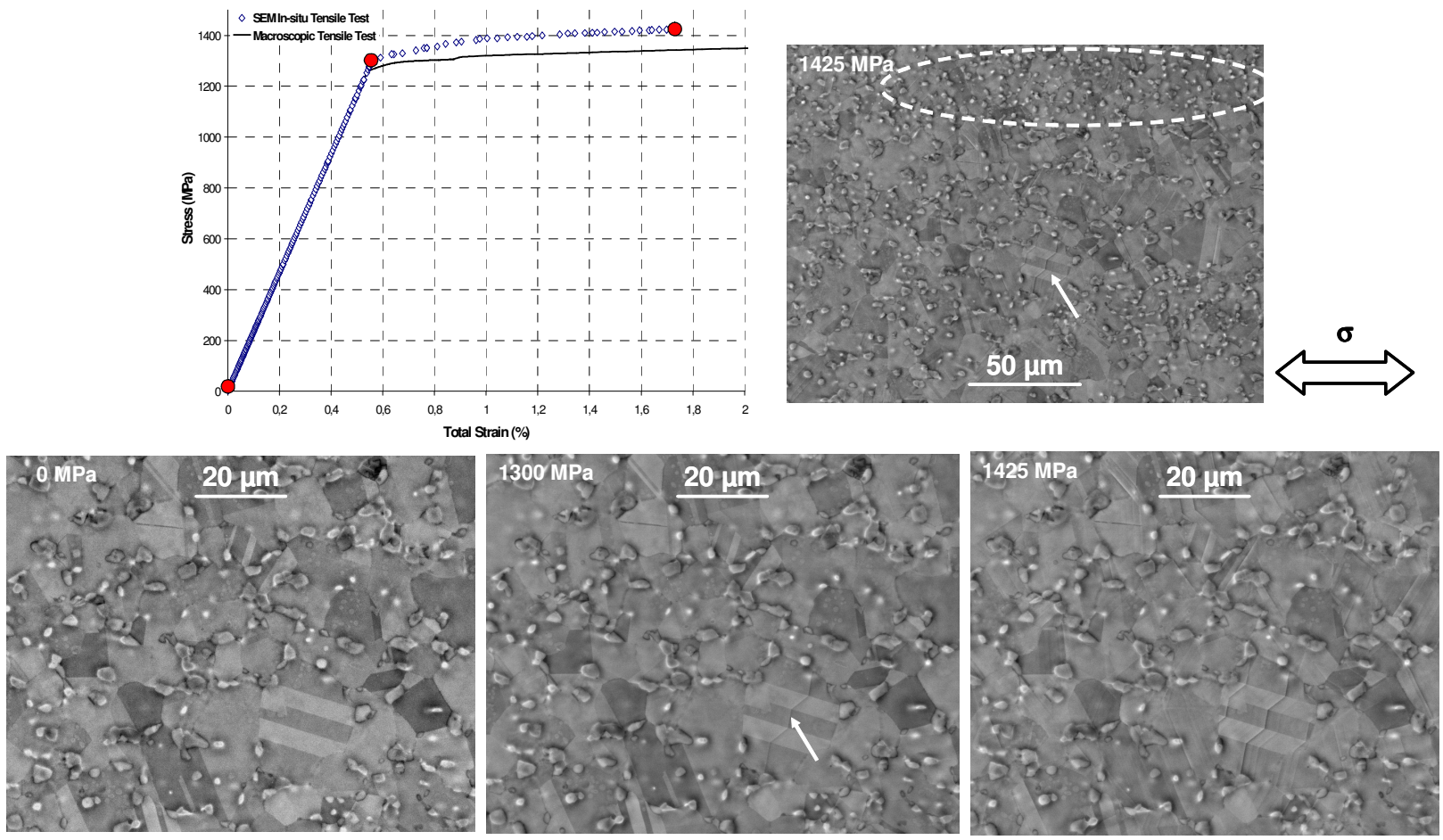

Figure 8. SEM in-situ tensile test performed on the highest YS sub-solvus microstructure and the corresponding microstructures at specific positions (red dots) of the tensile curve

Considering the CR alloy, first slip traces occur in several grains of the sample, all corresponding to high Schmid factors close to 0.5. Increasing the deformation results in the multiplication of the slip bands (see for example Figure 9), with the activation of new slip systems less highly loaded (Schmid factors between 0.3 and 0.42). Moreover, it is interesting to note that some slip bands occurring in a grain entails a diffuse plasticity in adjacent grain not favorably oriented to initiate slip bands (see dotted area in Figure 9). This diffuse plasticity is revealed in the BSE mode of the microscope by contrast changes near grain boundaries (see the three pictures of Figure 9) and by local crystallographic rotations at each slip band tip (see orientation map in Figure 9 focused on a grain boundary between two grains exhibiting either a high density of slip traces - the red one or a very small density - the blue one). Clearly, this plasticity processes are more developed (in terms of fraction of grains plastically deformed, number of activated slip systems, density of slip bands) in the grains of the CR alloy even though the macroscopic plastic strain reached $(0.36 \%)$ remains significantly lower than for the HS alloy (1.15\%). 


\section{Discussion}

The room temperature tensile properties of a forged U720Li have been maximized for sub-solvus heat treatments followed by oil quench, using solution temperature of either $1080 \mathrm{C}$ or $1120 \mathrm{C}$. Moreover, it has been demonstrated that the aging treatment producing the best tensile properties is $16 \mathrm{~h} 760 \mathrm{C} / \mathrm{AQ}+24 \mathrm{~h} 650 \mathrm{C} / \mathrm{AQ}$, independently of the ST. Based on those observations, it appears that two kinds of microstructure are optimal to achieve high YS alloys:

- a small grained alloy (average diameter 4-5 $\mu \mathrm{m}$ ) with a quite high volume fraction of primary $\gamma^{\prime}\left(\gamma_{\text {I }}^{\prime}\right.$ volume fraction $\left.\approx 20 \%\right)$ and a bimodal distribution of intragranular $\gamma^{\prime}$ built with undissolved secondary $\gamma^{\prime}\left(\gamma_{\text {IIU }}^{\prime}\right)$ and cooling secondary $\gamma^{\prime}\left(\gamma_{\text {IIc }}^{\prime}\right)$ whose average diameter is in the range $15-25 \mathrm{~nm}$.

- a somewhat coarser grained alloy (average diameter 12-14 $\mu \mathrm{m}$ ) built with a moderate volume fraction of primary $\gamma^{\prime}\left(\gamma_{\mathrm{I}}^{\prime}\right.$ volume fraction $\left.\approx 15 \%\right)$ and a single modal distribution of intragranular $\gamma^{\prime}$ built with only cooling secondary $\gamma^{\prime}\left(\gamma_{\text {IIc }}\right)$ whose average diameter is in the range $25-40 \mathrm{~nm}$.

This second microstructure is somewhat similar to that of Jackson and Reed designed to maximize both tensile properties (at room temperature and $600 \mathrm{C}$ ) and creep properties at $750 \mathrm{C}$ [11]. Their "optimum" microstructure was obtained using a 4h ST at 1105 C/OQ followed by a $24 \mathrm{~h}$ aging treatment at $700 \mathrm{C} / \mathrm{AQ}$ leading to a grain size of 11-12 $\mu \mathrm{m}$ and a $\gamma^{\prime}$ microstructure built with $14 \%$ of intergranular $\gamma_{I}^{\prime}$ and a bimodal distribution of intragranular $\gamma^{\prime}$ particles whose average diameters are $110 \mathrm{~nm}$ and $40 \mathrm{~nm}$.
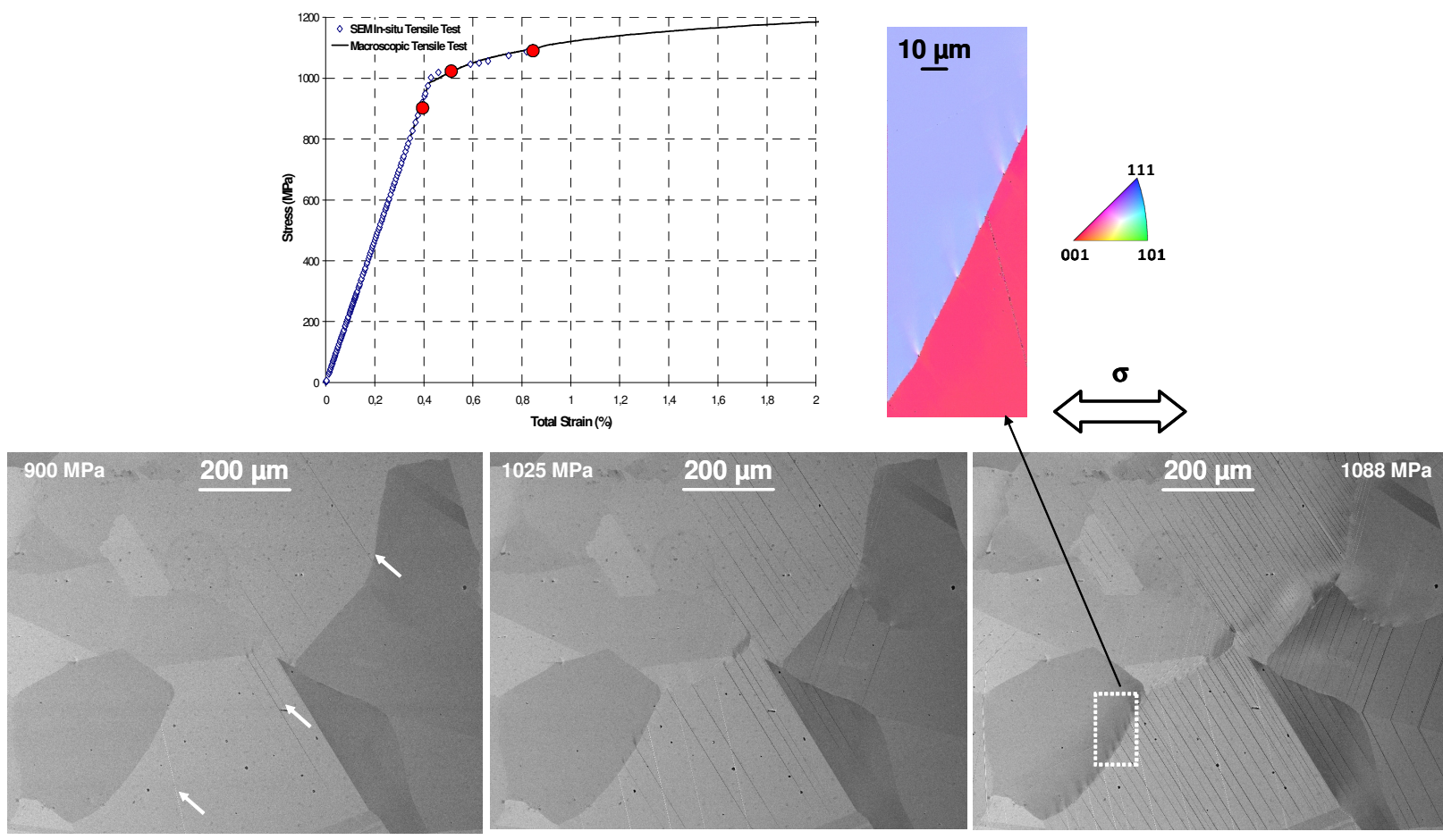

Figure 9. SEM in-situ tensile test performed on the highest YS super-solvus microstructure and the corresponding microstructures at specific positions (red dots) of the tensile curve 
For a ST of $1105 \mathrm{C}$, Jackson and Reed showed that optimal properties are conferred by placing a maximum of tertiary $\gamma^{\prime}$ in the size range $23-40 \mathrm{~nm}$ and limiting the secondary $\gamma^{\prime}$ content as practical [11]. In addition, they claimed that the 'standard' aging treatment of $24 \mathrm{~h}$ at $650 \mathrm{C} / \mathrm{AQ}$ $+16 \mathrm{~h}$ at $760 \mathrm{C} / \mathrm{AQ}$ which is suggested for U720 appears not to be optimal for U720Li since it leaves tertiary $\gamma^{\prime}$ in an overaged condition. Our study is in good agreement with those recommendations but we also demonstrate that tensile properties, especially $\mathrm{YS}$, have to be rationalized by the grain size. If primary $\gamma^{\prime}$ were not evidenced to be sources of room temperature plasticity during SEM in-situ tensile tests, they indirectly control YS by limiting grain growth during ST by means of Zener pining process. Indeed, analyzing SEM in-situ tensile tests, especially those performed on sub-solvus alloys, yields at considering that the main YS controlling parameter is grain size since plasticity initiation occurred in the coarsest grains. Therefore, to achieve the highest YS by means of thermal treatments (i.e. the Direct Aged procedure after forging is not considered here), a compromise has to be found between keeping a small grain size (i.e. lowering the solution temperature) and increasing the intragranular $\gamma^{\prime}$ volume fraction (i.e. increasing the solution temperature to dissolve $\gamma_{\mathrm{I}}^{\prime}$ ). Based on both our study and Jackson and Reed one [11], this can be done using ST in the sub-solvus investigated temperature range $1080 \mathrm{C}-1120 \mathrm{C}$ here. Additionally, we feel that another possibility could be based on designing a partial solution treatment (i.e. using short duration) at higher temperature $(1030 \mathrm{C}<\mathrm{T}<1055 \mathrm{C})$ to dissolve a substantial fraction of $\gamma_{\mathrm{I}}^{\prime}$, without entailing pronounced grain growth. As observed in Fig. 10, a practical guideline to follow to achieve the highest tensile properties, whatever ST and aging treatment, is to reach an interparticle spacing in the range 15-40 nm. Such a new YS guideline is quite interesting since recommendations are often formulated on the $\gamma^{\prime}$ size and volume fraction for a given grain size while plasticity usually initiates in the $\gamma$ matrix and is hence mainly controlled by interparticle spacing.

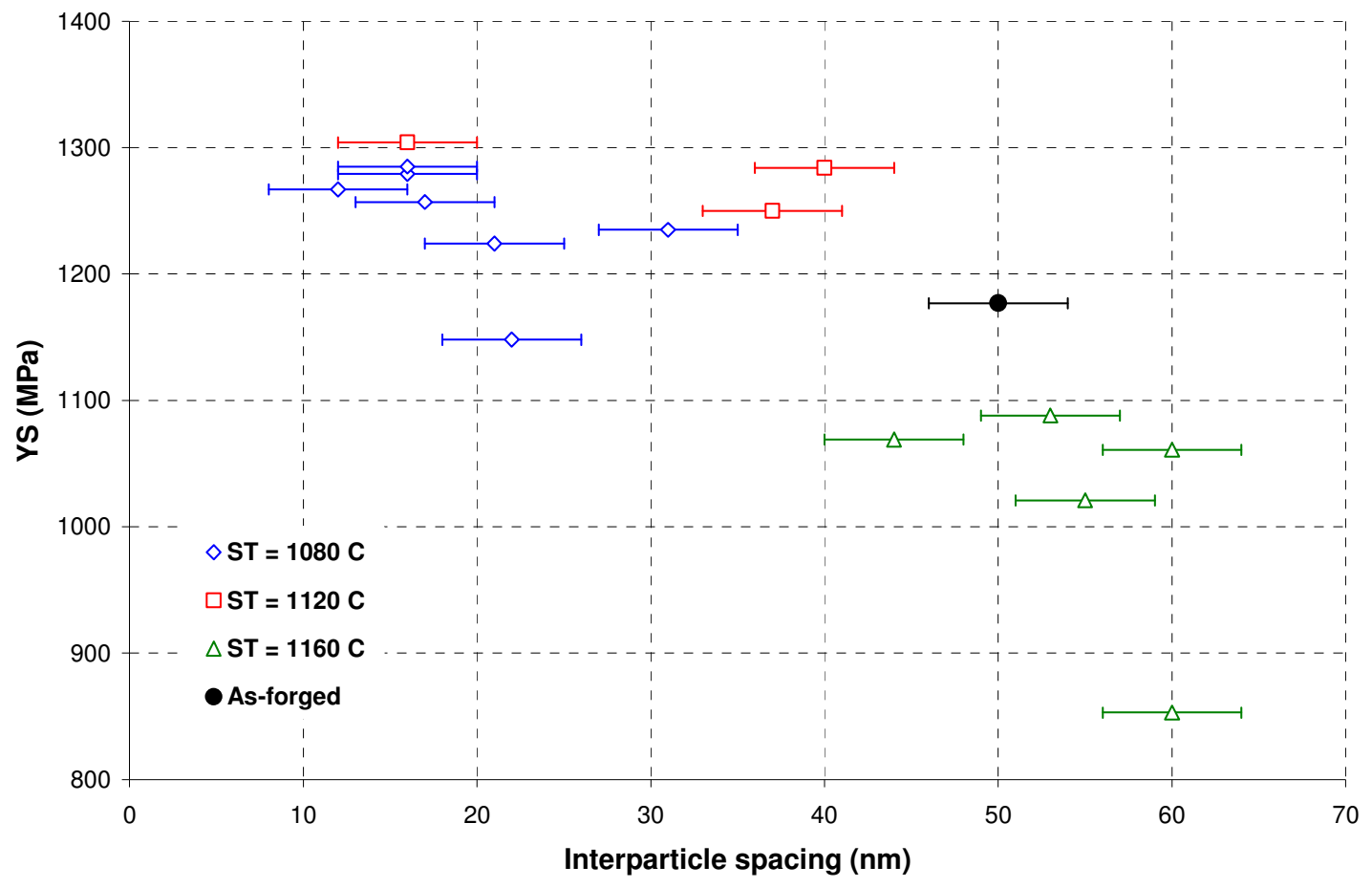

Figure 10. Correlation of the YS with the interparticle spacing. 
All the results presented in this study only deal with tensile properties at room temperature. Further characterizations focussed on both high temperature (in the $650 \mathrm{C}-800 \mathrm{C}$ range) tensile and creep properties will be performed on the presented microstructures.

\section{Concluding remarks}

Room temperature tensile properties of U720Li alloy have been studied using different thermal treatments. The effects of solution temperature (either sub- or super-solvus), cooling rates after solution treatment and aging dwells temperature and length were investigated. Correlation between microstructural characteristics (grain size, $\gamma^{\prime}$ volume fraction of each class of particles and $\gamma^{\prime}$ distribution) and tensile properties leads to the conclusion that a unique optimal microstructure with respects to both YS and UTS does not exist. Based on SEM in-situ tensile tests, it was identified that the main YS controlling parameter is grain size which can be counterbalanced by the effect of an increased intragranular $\gamma^{\prime}$ volume fraction and an optimized size distribution controlled by aging treatment.

\section{Acknowledgements}

This study is part of an on-going effort started in 1999 between Aubert \& Duval and Turbomeca

- SAFRAN group and devoted to the improvement U720Li mechanical properties [18-20].

\section{References}

1. F.E. Sczerzenie and G.E. Maurer. "Development of Udimet 720 for high strength disk applications", (Paper presented at Superalloys 1980, Metals Park, OH, 1980), 573-580.

2. S.K. Jain, B.A. Ewing, and C.A. Yin. "The development of improved performance PM UDIMET 720 Turbine disks", (Paper presented at Superalloys 2000, Seven Springs, Champion, PA, USA, 2000), 785-794.

3. D. Helm and O. Roder. "Influence of long term exposure in air on microstructure, surface stability and mechanical properties of Udimet 720Li", (Paper presented at Superalloys 2000, Seven Springs, Champion, PA, USA, 2000), 487-493.

4. R.C. Reed, The Superalloys - Fundamentals and Applications (Cambridge, UK: Cambridge University Press, 2006).

5. S. Dubiez et al., "Effect of the microstructure on the creep behaviour of PM Udimet 720 superalloy - experiments and modeling", Material Science and Engineering, A 387-389 (2004), p 599-603.

6. M. Mazière et al., "Overspeed burst of elastoviscoplastic rotating disks - Part I: Analytical and numerical stability analyses", European Journal of Mechanics A/Solids, 28 (2009), 3644. 
7. M. Yarnaguchiy et al. "Grain size prediction of alloy 718 billet forged by radial forging machine using numerical and physical simulation", (Paper presented at Superalloys 718, 625, 706 and Various Derivatives, 2001), 291-300.

8. F. Bridier, P. Villechaise, and J. Mendez, "Analysis of the different slip systems activated by tension in a $\alpha / \beta$ titanium alloy in relation with local crystallographic orientation", Acta Materialia, 53 (2005), 555-567.

9. T. Billot, "Comportement et endommagement en fatigue et fatigue-fluage à haute température de différents états microstructuraux du superalliage base-nickel Udimet 720", (PhD.Thesis, ENSMA, 2010).

10. D.U. Furrer and H.-J. Fecht. "Microstructure and mechanical property development in superalloy U720Li", (Paper presented at Superalloys 200, Seven Springs, Champion, PA, USA, 2000), 415-424.

11. M.P. Jackson and R.C. Reed, "Heat treatment of UDIMET 720Li: the effect of microstructure on properties", Material Science and Engineering, A259 (1999), 85-97.

12. R. Radis et al., "Multimodal size distribution of $\gamma^{\prime}$ precipitates during continuous cooling of UDIMET 720 Li", Acta Materialia, 57 (2009), 5739-5747.

13. D.U. Furrer and H.-J. Fecht, " $\gamma$ ' formation in superalloy U720Li", Scripta Materialia, 40 (11) (1999), 1215-1220.

14. J.R. Vaunois, "Etude de l'influence du traitement thermique sur la microstructure et les propriétés en traction du superalliage Udimet 720" (Internal Report, Aubert et Duval - Site des Ancizes, 2010).

15. J. Mao et al., "Cooling precipitation and strengthening study in Powder Metallurgy Superalloy U720Li", Metallurgical and Materials Transactions, 32A (2001), 2441-2452.

16. I.M. Lifshitz and V.V. Slyozov, Journal of Physical Chemistry solids, 19 (1/2) (1961), 35-50.

17. C. Wagner, Zeitschrift für Elektrochemie, 65 (7/8) (1961), 581-591.

18. T. Balmary, "Approfondissement des relations microstructures/caractéristiques mécaniques de traction du superalliage Udimet 720 forgé" (Internal report, Turbomeca - SAFRAN group, 2000).

19. A. Caron, "Approfondissement des relations microstructures/caractéristiques mécaniques en fonction des traitements thermomécaniques sur 1'Udimet 720" (Internal report, Turbomeca SAFRAN group, 2006).

20. A. Devaux, "Amélioration des propriétés mécanique de l'Udimet 720" (Internal report, Turbomeca - SAFRAN group, 2004). 